\title{
Inhalt des XXIV. Bandes
}

\section{Romanistische Abteilung.}

Seite

Theodor Mommsen, von der Redaktion . . . . . . . . V

Contardo Ferrini, von der Redaktion . . . . . . . . . VII

Bekker, E. J., Streitfragen aus dem Aktionenprozeßrecht . . 344

Gradenwitz, Otto, Ältere und neuere formula arbitraria . . 238

Hellmann, Zur Terminologie der römischen Rechtsquellen in der Lehre von der Unwirksamkeit der juristischen Tatsachen (Schluß) . . . . . . . . . . . . . 50

Hölder, Eduard, Die litis contestatio des Formularprozeßes . 197

Krüger, Paul, Bemerkungen zu Dig. 40, 7, $29 \S 1$ (Pomponius ad Q. Mucium) . . . . . . . . . . . . . 193

-, -, Der Kommentar zu Gai Institutiones in Autun . . . . 375

Lenel, O., Zur Form der klassischen Litiskontestation . . . . 329

Levy, Ernst, Zur Lehre von der Muciana cautio im klassischen römischen Recht . . . . . . . . . . . . . . . 122

von Mayr, Robert, Condictio incerti . . . . . . . . 258

Mommsen, Theodor, Die Popularklagen . . . . . . . . 1

Puntschart, Paul, Über den ursprünglichen Sinn des Wolf-

Symbols der Stadt Rom . . . . . . . . . . 252

Schloßmann, Nemo sibi ipse causam possessionis mutare potest 13

—, -, Zur Geschichte des römischen Kaufes . . . . . . . . 152

,-- , Der Vindex bei der in ius vocatio . . . . . . . . . 279

\section{Miszellen:}

Beneschewitz, Wladimir, Codex Iustineus? . . . . . 409

Erman, H., Recht und Prätor - aus Anlaß von Ehrlichs Buch 421

Gradenwitz, O., Nachtrag zu dem Aufsatz: Reskripte auf

Papyrus, Bd. 23 S. 356 . . . . . . . . . . . . 416

Lenel, Zur Ableitung der Worte vas und praes . . . . . 414 
Seito

I. M., Die Monumenta des Manilius und das Ius Papirianum 419

Schneider, A., Zu dem von Mommsen Bd. XXII S. 195 abgedruckten Papyrus . . . . . . . . . . . . . 414

\section{Literatur:}

Nikolsky, B. W., Die Schenkungen zwischen Ehegatten.

I. Bd. 1. Lief. . . . . . . . . . . . . . . . . 441 Besprochen von Baron A. Nolde.

de Ruggiero, Roberto, J papiri Greci e la "stipulatio duplae“. - Stockar, Hans, Über den Entzug der väterlichen Gewalt im römischen Recht. - Chauvin, V., La constitution du Code Théodosien sur les agri deserti et le Droit arabe . . . . . . . . . . . . 451 Besprochen von B. Kübler.

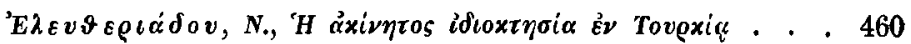
Besprochen von Demetrius Pappalias.

v. Koschembahr-Lyskowski, J., Die condictio als Bereicherungsklage im klassischen römischen Recht Bd. 1462 Besprochen von Hngo Krüger.

Costa, Emilio, Corso di storia del diritto romano dalle origini alle compilazioni Giustinianee Vol. I . . . . 471 Besprochen von Leopold Wenger.

Contuzzi, Francesco P., Il Codice civile nei rapporti del diritto internazionale privato. Vol. II . . . . . . . 478 Besprochen von A. Mendelssohn-Bartholdy. 